\title{
Upper Gasterointestinal Endoscopy Finding in a Patient with Obstructive Jaundice
}

\author{
Mohamed Alshekhani* \\ Faculty of Medical Sciences, University of Sulaimani, Iraq
}

Submission: September 08, 2017; Published: November 16, 2017

"Corresponding author: Mohamed Alshekhani, University of Sulaimani, Faculty of Medical Sciences, School of Medicine, Department of Medicine, Kurdistan Center for Gastroenterology \& Hepatology, Iraq, Email: shaikhanimohammad@gmail.com

\begin{abstract}
Background: The duodenoscope used for endoscopic retrograde cholangiopancreatography, is a side viewing and may miss some unexpected obstructive esophageal of duodenal lesions which may prevent access to the ampulla of vater and lead to the procedure failure.
\end{abstract}

Aims of the study: To determine the upper GI endoscopic finding in patients with obstructive jaundice who are going to undergo endoscopic retrograde cholangiopancreatography \& the significance of these finding in directing the ERCP team to be more cautious during the procedure or changing the decision either to postpond or cancel the procedure.

Material and method: This study was done in kurdistan center for gastroenterology and hepatology in suleimanya, between 1st June 2008 to1st August 2016. Two hundred patients with obstructive jaundice had been studied, aproper history and physical examination was undertaken. Upper endoscopy was done by Olympus EVIS lucera 2005. Informed consent was obtained from all patients. H. pylori serology was sent for all patients.

Result: Two hundred cases with obstructive jaundice were studied, 120 cases were male and 80 cases were female. The entire patient has obstructive jaundice, the most common presenting complain in association with jaundice was anorexia \& weight loss. H. pylori serology was done for all patients \& was positive in 140 patients more among the 117 patients with abnormal endoscopic findings. The most common cause of obstructive jaundice were as follow: common bile duct stones, cholangiocarcinoma; pancreatic head cancer, benign biliary stricture, asciola hepatic \& intrabiliary rupture of liver hydrated cysts. The abnormal OGD findings included; Duodenal ulcer DU 20, Gastric ulcer GU6, GERD 10, Esophageal peptic stricture 2, benign gastric outlet obstruction 4, antral gastropathy 50, duodenitis 12 , gastric erosion 10 \& malignant gastric outlet obstruction 3 . These results benefited the ERCP team to be more cautious during the procedure in those 109 patients with the less serious non obstructive pathologies, while led to delay the procedure in the 6 patients with benign obstructive lesions until improvement with therapy $\&$ to consider canceling the procedure in the 2 patients with malignant gastric outlet obstruction\& search for other management options.

Conclusion: In this study population with high prevalence of $H$. pylori infection and patients with delayed pancreato-biliary cancer diagnosis, upper endoscopy, a relatively cheap \& minimally-invasiveprocedure, found to be of benefit in directing the ERCP team to be more cautious during the procedure or change the decision either to postpond or cancel the procedure

Keywords: Obstructive jaundice; OGD; ERCP

\section{Introduction}

Obstructive or surgical jaundice is a condition in which there is biochemical evidence of biliary obstruction namely raised direct bilirubin, raised serum alkhaline phosphatase with normal or near normal transaminases (except when the cause is biliary cholelithiasis when the transaminases may be elevated too) and there is evidence of extrahepatic or less commonly intrahepatic biliary obstruction on imaging as abdominal ultrasound, Endoscopic ultrasound(EUS) or magnetic resonance cholangiopancreatography (MRCP) or endoscopic retrograde choalngiopancreatography (ERCP) [1]. Other medical causes of intrahepatic cholestasis should be excluded when the clinical picture is not so clear and there no clear obstruction on imagings, such as primary biliary cholangitis, primary sclerosing cholangitis, autoimmune IgG4-related cholangitis or auoimmune or viral or drug hepatitis [2].

Patients with obstructive jaundice are usually evaluated nowadays by non-invasive imaging such as abdominal ultrasound, MRCP \& EUS [3]. The ERCP, being invasive and with serious complications including perforation \& acute pancreatitis with 
high morbidity \& mortality, is usually left for conditions in which a definite therapeutic intervention is indicated such as removing obstructing stones or other benign pathologies or when stenting is needed to bypass the biliary obstruction specially when acute cholangitis is present [4].

Upper GI pathologies may be more common in patients with obstructive jaundice because in such condition the obstructed bile may be excreted through alternative pathways such the upper GI mucosa which may ilicit toxic effects and it is well known that peptic ulcer disease is more common in patients with organ failure including hepatic failure [5].

ERCP requires patent upper gastrointestinal pathways to get safe access to the ampulla of Vater [6]. The duodenoscope used during ERCP to get access to the bilo-pancreatic ducts, is a sideviewing scope and may not visualize potential obstructive and nonobstructive upper GI pathologies and may make struggling to get access to the ampulla of Vater dangerous in cases of obstructive duodenal \& esophageal lesions [7]. Doing routine upper endoscopy in patients with obstructive jaundice prior to ERCP discovers such pathological easily \&may give the ERCP team important information. Although most international gastrointestinal societies do not recommend routine upper endoscopy prior to ERCP, first because benign upper GI pathologies are less common in western societies because of the decreasing prevalence of $H$. pylori infection and second because most of duodenal obstructions can be evaluated by the above mentioned imaging prior to ERCP $[8,9]$.

This study was done to find the upper endoscopic findings in patients with obstructive jaundice and to find whether doing this procedure can benefit the ERCP team to be better prepared for the procedure \& hence a safer procedure.

\section{Patients and Methods}

This study was done in kurdistan center for gastroentroloy and hepatology in suleimanyah-Iraqi Kurdistan-Iraq, between $1^{\text {st }}$ June 2008 to $1^{\text {st }}$ August 2016. Two hundred patients with obstructive jaundice had been studied. Obstructive jaundice was diagnosed when there was obstructive biochemical liver chemistries \& clear obstruction on non-invasive imaging. A proper history and physical examination was undertaken. Upper endoscopy was done by Olympus EVIS Lucera 2005. Informed consent was obtained from all patients. H. pylori serology was sent for all patients.

\section{Results}

Two hundred cases with obstructive jaundice were studied, 120 cases were male and 80 cases were female. All the patient has obstructive jaundice, the most common presenting complains in association with jaundice were anorexia \& weight loss. $H$. pylori serology was done for all patients \& was positive in 140 (70\%) patients more among the 117 patients with abnormal endoscopic findings. The most common cause of obstructive jaundice were as follow and shown in Table 1: common bile duct stones, cholangiocarcinoma; pancreatic head cancer, benign biliary stricture, fasciola hepatic \& intrabiliary rupture of liver hydatid cysts.

Table 1:

\begin{tabular}{|c|c|c|}
\hline Causes of Obstructive Jaundice & Number & Percentage \\
\hline Cholelithiasis & 108 & $54 \%$ \\
\hline Choalgicarcinoma & 26 & $13 \%$ \\
\hline Cancer head of pancrease & 16 & $08 \%$ \\
\hline Benign biliary stricture & 10 & $05 \%$ \\
\hline Biliary Fasciola hepatica & 5 & $2.5 \%$ \\
\hline Intrabiliary rupture of liver hydatid & 16 & $08 \%$ \\
\hline Undiagnosed & 19 & $9.5 \%$ \\
\hline
\end{tabular}

The abnormal OGD findings were found in in 117 patients shown in Table 2 and included; Duodenal ulcer DU 20, Gastric ulcer GU 6, GERD 10, Esophageal peptic stricture 2, benign gastric outlet obstruction 4 , isolated antral gastropathy 50 , duodenitis 12 , gastritis and gastric erosions 10\& malignant gastric outlet obstruction 3.

Table 2:

\begin{tabular}{|c|c|c|}
\hline $\begin{array}{c}\text { Abnormal OGD } \\
\text { Findings }\end{array}$ & Number & Percentage \\
\hline Duodenal ulcer & 20 & $17.1 \%$ \\
\hline Gastric ulcer & 06 & $5.1 \%$ \\
\hline GERD & 10 & $1.7 \%$ \\
\hline $\begin{array}{c}\text { Oesophageal peptic } \\
\text { stricture }\end{array}$ & 04 & $3.4 \%$ \\
\hline $\begin{array}{c}\text { Benign gastric outlet } \\
\text { obstruction }\end{array}$ & 12 & $42.7 \%$ \\
\hline $\begin{array}{c}\text { Isolated antral } \\
\text { gastropathy }\end{array}$ & 10 & $10.2 \%$ \\
\hline Duodenitis & 03 & $8.5 \%$ \\
\hline $\begin{array}{c}\text { Gastritis and gastric } \\
\text { erosions }\end{array}$ & 117 & $100 \%$ \\
\hline $\begin{array}{c}\text { Malignat gastric outlet } \\
\text { obstruction }\end{array}$ & & $2.5 \%$ \\
\hline & & \\
\hline
\end{tabular}

These results benefited the ERCP team to proceed with the procedure if indicated, but to be more cautious during the procedure in those 82 patients with the less serious and non obstructive pathologies, while led to delay the procedure in the 32 patients with peptic ulcerations and benign obstructive lesions waiting improvement with appropriate therapy\& to consider canceling the procedure in the 3 patients with malignant gastric outlet obstruction \& search for other management options.

\section{Discussion}

This study was done to find the upper endoscopic findings in patients with obstructive jaundice and to find whether doing that before ERCP can benefit the ERCP team to be better prepared for the procedure \& hence have a safer procedure.

This study involved 200 patients with obstructive jaundice due to various causes. The prevalence of $H$. pylori by positive serology 
was high (70\%) among these patients, more among those patients with abnormal upper endoscopic finding supporting the role of $H$. pylori in these patients. The obstructive jaundice state also may potentiated the effect of $H$. pylori infections in these patients as it is found that excretion of bile in upper GI tract may have toxic effects on the mucosa 10 and in addition organ failure is well known to increase the risk of peptic ulcer disease $[10,11]$.

Table 1, shows the causes of obstructive jaundice in these patient series which included biliary cholelithiasis as the most common cause followed by cholangiocarcinoma, carcinoma head of pancrease, benign biliary stricture, fasciola hepatic, intrabiliary rupture of liver hydatid cysts and included 19 cases undiagnosed at the time of the finishing the study. These results are in concordance with other studies, although the prevalence of parasitic causes of obstructive jaundice may differ according to the geographical location [12-14].

Table 2, shows the lesions discovered by OGD and showed that 117 patients had abnormal OGD findings and included; Duodenal ulcer DU 20, Gastric ulcer GU 6, GERD 10, Esophageal peptic stricture 2 , benign gastric outlet obstruction 4 , isolated antral gastropathy 50, duodenitis 12, gastritis and gastric erosions 10 \& malignant gastric outlet obstruction 3. As mentioned above these patients are from a location with high $H$. pylori prevalence and had obstructive jaundice having bad effects on upper GI tract, explaining the high prevalence of abnormal endoscopic findings in those patients [12]. Very few studies had been done on the upper endoscopic findings in patients with obstructive jaundice because western gastrointestinal societies do not recommend routine upper endoscopy in patients with obstructive jaundice prior to indicated ERCP [8]. One study was found addressing this subject but the duration of the study was shorter than the current study and hence the upper endoscopic finding did not include some of our findings [15-19].

These results benefited the ERCP team to proceed with the procedure if indicated, but to be more cautious during the procedure in those 82 patients with the less serious and non obstructive pathologies, while led to delay the procedure in the 32 patients with peptic ulcerations and benign obstructive lesions waiting improvement with appropriate therapy \& to consider canceling the procedure in the 3 patients with malignant gastric outlet obstruction \& search for other management options.

No other studies were found to confirm this approach, but we think that in developing countries with high $H$. pylori prevalence and in patients with obstructive jaundice including important malignant causes which may involve the gastric outlet too, it may be a reasonable approach to recommend pre-ERCP upper GI endoscopy to benefit the ERCP team in planning a better and safer ERCP, especially when the advanced imaging technologies such as MRCP \&EUS are not available or accessible because of their costs.

\section{References}

1. Center SA (2009) Diseases of the gallbladder and biliary tree. Vet Clin North Am Small Anim Pract 39(3): 543-598.
2. Marrelli D, Caruso S, Pedrazzani C, Neri A, Fernandes E, et al. (2009) CA19-9 serum levels in obstructive jaundice: clinical value in benign and malignant conditions. Am J Surg 198(3): 333-339.

3. Bektaş M, Dökmeci A, Cinar K, Halici I, Oztas E, et al. (2010) Endoscopic management of biliary parasitic diseases. Dig Dis Sci 55(5): 1472-1478.

4. Lee JG (2011) Diagnosis and management of acute cholangitis. Nat Rev Gastroenterol Hepatol 13(2): 166-172.

5. Chu YC, Yang CC, Yeh YH, Chen CH, Yueh SK (2009) Double-balloon enteroscopy application in biliary tract disease-its therapeutic and diagnostic functions. Gastrointest Endosc 70(3): 601-602.

6. Aabakken L, Bretthauer M, Line PD (2007) Double-balloon enteroscopy for endoscopic retrograde cholangiography in patients with a Rouxen-Y anastomosis. Endoscopy 39(12): 1068-1071.

7. Nanashima A, Abo T, Sakamoto I, Makino K, Sumida Y, et al. (2005) Three-dimensional cholangiography applying C-arm computed tomography in bile duct carcinoma: a new radiological technique. Hepatogastroenterology 56(91-92): 615-618.

8. Chathadi KV, Chandrasekhara V, Acosta RD, Decker GA, Early DS, et al. (2015) The role of ERCP in benign diseases of the biliary tract; Gastrointest Endosc 81(4): 795-803.

9. Dumonceau JM, Heresbach D, Devière J, Costamagna G, Beilenhoff U, et al. (2011) Biliary stents: models and methods for endoscopic stenting. Endoscopy 43(7): 617-626.

10. G Tell, S Gustincich (2009) Redox state, oxidative stress, and molecular mechanisms of protective and toxic effects of bilirubin on cells; Current pharmaceutical design. Curr Pharm Des 15(25): 2908-2914.

11. AP Kirk, JS Dooley, RH Hunt (1980) Peptic ulceration in patients with chronic liver disease Digestive diseases and sciences. Digestive Diseases and Sciences 25(10): 756-760.

12. (2011) Board of Governors of the Society of American Gastrointestinal and Endoscopic Surgeons (SAGES). Guidelines for Training in Diagnostic and Therapeutic Endoscopic Retrograde Cholangiopancreatography (ERCP); the Society of American Gastrointestinal and Endoscopic Surgeons.

13. Niu H, Gao W, Cheng J, Liu B, Li Y, et al. (2012) Improvement of percutaneous transhepatic biliary internal-external drainage and its initial experience in patients with malignant obstruction of the upper biliary tree. Hepatogastroenterology 59(117): 1368-1373.

14. Hanada K, Iiboshi T, Ishii Y (2009) Endoscopic ultrasound-guided choledochoduodenostomy for palliative biliary drainage in cases with inoperable pancreas head carcinoma. Dig Endosc 21(Suppl 1): S75-S78.

15. Maranki J, Hernandez AJ, Arslan B, Jaffan AA, Angle JF, et al. (2009) Interventional endoscopic ultrasound-guided cholangiography: long-term experience of an emerging alternative to percutaneous transhepatic cholangiography. Endoscopy 41(6): 532-538.

16. Dhir V, Itoi T, Khashab MA, Park DH, Yuen Bun Teoh A, et al. (2015) Multicenter comparative evaluation of endoscopic placement of expandable metal stents for malignant distal common bile duct obstruction by ERCP or EUS-guided approach. Gastrointest Endosc 81(4): 913-923.

17. Mutignani M, Iacopini F, Perri V, Familiari P, Tringali A, et al. (2009) Endoscopic gallbladder drainage for acute cholecystitis: technical and clinical results. Endoscopy 41(6): 539-546.

18. Lin H, Li S, Liu X (2016) The safety and efficacy of nasobiliary drainage versus biliary stenting in malignant biliary obstruction: A systematic review and meta-analysis. Medicine (Baltimore) 95(46): e5253.

19. Jaganmohan S, Lee JH (2012) Self-expandable metal stents in malignant biliary obstruction. Expert Rev Gastroenterol Hepatol 6(1): 105-114. 
This work is licensed under Creative Commons Attribution 4.0 License DOI: 10.19080/ARGH.2017.07.555717

\section{Your next submission with Juniper Publishers will reach you the below assets}

- Quality Editorial service

- Swift Peer Review

- Reprints availability

- E-prints Service

- Manuscript Podcast for convenient understanding

- Global attainment for your research

- Manuscript accessibility in different formats

( Pdf, E-pub, Full Text, Audio)

- Unceasing customer service

Track the below URL for one-step submission https://juniperpublishers.com/online-submission.php 